\title{
MOTIVASI DAN HASIL BELAJAR FISIKA PADA PEMBELAJARAN DARING DI MA HIDAYATUL INSAN
}

\author{
Nurhikmah Amalia ${ }^{1}$, Hadma Yuliani ${ }^{2}$, Mukhlis Rohmadi ${ }^{3}$ \\ nurhikmahamalia12@gmail.com \\ ${ }^{1,2,3}$ Program Studi Tadris (Pendidikan) Fisika, IAIN Palangka Raya, Palangka Raya, Indonesia
}

Received: 29 Oktober $2021 \quad$ Revised: 2 November 2021

Accepted: 11 Desember 2021

\begin{abstract}
COVID-19 has temporarily suspended educational and learning activities that require students to study at home for safety and health. Efforts are being made to change conventional learning into online learning using modern technology by developing internet-based learning. This study aims to determine: (1) how the students' learning motivation online learning (2) how the student learning outcomes in online learning. The type of research that will be conducted is descriptive quantitative. Sampling was purposive sampling, the sample used was class X MA Hidayatul Insan Palangka Raya. The instruments used in this study were a learning motivation questionnaire and student learning outcomes tests. Based on the results of this study, students' learning motivation in online learning was obtained as many as $80 \%$ of students in the medium category and $20 \%$ had students' motivation in the low category. The analysis of the data above, it shows that the average student motivation is in the medium category with an average number of 68.2. And student learning outcomes show that there are 3 students who have not completed and 7 students have completed online learning. With a percentage of 70\% completeness and the overall average score of students is 77.3.
\end{abstract}

\begin{abstract}
Abstrak: COVID-19 menghentikan sementara kegiatan pendidikan dan pembelajaran yang mengharuskan siswa belajar di rumah demi keselamatan dan kesehatan. Upaya yang dilakukan adalah mengubah pembelajaran konvensional menjadi pembelajaran daring menggunakan teknologi modern dengan mengembangkan pembelajaran berbasis internet. Penelitian ini bertujuan untuk mengetahui: (1) bagaimana motivasi belajar siswa pembelajaran daring (2) bagaimana hasil belajar siswa pada pembelajaran daring. Jenis penelitian yang akan dilakukan adalah kuantitatif deskriptif. Pengambilan sampel secara purposive sampling, sampel yang digunakan adalah kelas X MA Hidayatul Insan Palangka Raya. Instrumen yang digunakan dalam penelitian ini adalah angket motivasi belajar dan tes hasil belajar siswa. Berdasarkan hasil penelitian ini, Motivasi belajar siswa pada pembelajaran daring diperoleh sebanyak $80 \%$ siswa pada kategori sedang dan $20 \%$ memiliki motivasi belajar siswa dengan kategori rendah. Dari analisis data di atas menunjukkan bahwa ratarata motivasi siswa tergolong pada kategori sedang dengan jumlah rata-rata sebesar 68,2. Dan hasil belajar siswa menunjukkan bahwa terdapat 3 orang siswa yang belum tuntas dan 7 orang siswa sudah tuntas pada pembelajaran daring. Dengan persentase ketuntasan $70 \%$ dan rata-rata keseluruhan skor siswa adalah 77,3.
\end{abstract}

Kata kunci : hasil belajar, motivasi belajar, pembelajaran daring 


\section{PENDAHULUAN}

Pandemi COVID-19 membuat pembelajaran ditutup sementara, siswa dituntut untuk bisa belajar di rumah demi kesehatan dan keamanan sehingga pengajar harus memberikan pelajaran secara daring (online). Saat ini, Kebutuhan pendidikan yang belum pernah ada sebelumnya dengan kemajuan teknologi dan ilmu pengetahuan, menuntut masyarakat untuk belajar dengan giat terus menerus dan memperbaharui ilmunya. Metode pembelajaran saat ini berbeda dengan masa lalu yang terbatas pada sekolah dan orang membutuhkan informasi baru atau yang diperoleh kapan saja, di mana saja (Zubaidah, 2016.). Beberapa puluh tahun yang lalu, akses informasi yang tak terbatas merupakan sesuatu yang, karena pendidikan dan pembelajaran hanya untuk orang-orang yang berpengetahuan dan mampu dari segi materi Timbulnya teknologi pc serta internet bisa membuat akses data jadi gampang serta murah. Internet timbul pada tahun 1980-an serta dengan kilat menyebar ke segala dunia (Chadwick, 2003). Pada saat yang sama, kemajuan teknologi komputer telah membuat komputer dan telepon seluler berkecepatan tinggi dapat diakses di banyak rumah, sekolah dan kantor, sehingga orang dapat mengakses informasi kapan saja dan di mana saja (Jamaludin et al., 2020).

Terlepas dari kemajuan teknologi, penelitian tentang pembelajaran guru semakin meningkat dan ditekankan bahwa siswa lebih cenderung menerima informasi dan tanggapan pasif terhadap lingkungan (Fathurrohman, 2017). Dalam teori belajar kognitif dan konstruktif menunjukkan bahwa siswa memiliki kemampuan untuk memproses informasi dan menciptakan basis pengetahuan individu, dan memperhitungkan pentingnya merancang instruksi berdasarkan kebutuhan individu mereka (Dede, 2008). Selain itu, penelitian inovatif Bloom telah menunjukkan manfaat dari pelatihan kelompok individu dengan hasil yang sangat baik (Bloom, 1984). Studi Fisika saat ini menunjukkan bahwa siswa sering menguraikan informasi dari pengalaman mereka sendiri (Close et al., 2016). Saat ini, akademisi menggunakan internet sebagai alat pembelajaran, yaitu pembelajaran elektronik di mana konten pembelajaran tersedia online dan memberikan hasil ke kegiatan pembelajaran (Paulsen et al., 2003). Untuk memenuhi kebutuhan siswa, e-learning harus didorong oleh persyaratan kurikulum dan alat belajar yang baik (Kusmana, 2017). Desain alat pembelajaran yang mendefinisikan karakter dalam $e$ learning sangat penting untuk efektivitas pemahaman siswa. 
Upaya telah dilakukan untuk mengubah pembelajaran konvensional menjadi pembelajaran modern (Darmayanti et al., 2007). Penggunaan teknologi modern melalui pengembangan desain pembelajaran berbasis e-learning adalah pilihan yang tepat (Sulistyaningsih et al., 2017). Lebih dari sepuluh tahun, Amerika Serikat menggunakan e-learning dalam pendidikan (O’Donnell et al., 2015). Tidak dapat dihindari bahwa teknik pengajaran dan pembelajaran harus mencakup unsur pembelajaran daring berbasis pada komputer dan mencakup persiapan yang tepat untuk proses pembelajaran. Konsep yang mendasari pembelajaran daring meliputi kemandirian, keaktifan pembelajar, belajar dari masalah, dan pembelajaran berbasis kerja (Martens et al., 2004). Pembelajaran daring didasarkan pada konstruktivisme (Raiser, 2001) yang menekankan tanggung jawab siswa dalam mengelola proses belajar mereka sendiri.

Motivasi belajar merupakan dorongan dari dalam dan luar siswa untuk belajar melakukan perubahan perilaku, biasanya dengan banyak indikator pendukung. Motivasi belajar merupakan penggerak utama siswa yang memicu kegiatan belajar sehingga tujuan siswa dapat tercapai (Sardiman, 2008). Motivasi belajar berperan dalam pengembangan keinginan untuk belajar dan kegembiraan dan kemauan untuk belajar pada diri siswa. Siswa yang bermotivasi tinggi memiliki banyak energi untuk belajar, dan sebaliknya siswa yang tidak termotivasi untuk belajar mungkin tidak dapat melakukan kegiatan belajar dengan baik. Dalam proses belajar mengajar, stimulasi belajar sangat penting karena mempengaruhi hasil belajar siswa dengan motivasi belajar. Semakin kuat motivasi siswa maka akan semakin positif hasil belajar siswa (Saputra et al., 2018).

Hasil belajar siswa adalah pencapaian dari suatu tujuan pembelajaran dari siswa yang telah mengikuti proses belajar. Hasil belajar apabila telah belajar akan terjadi perubahan tingkah laku pada orang tersebut, misalnya dari tidak tahu menjadi tahu dan tidak mengerti menjadi mengerti (Gumay, O. P. U., Ariani, T., \& Putri, G. A, 2020). Tujuan pendidikan bersifat ideal, sedangkan hasil belajar bersifat nyata (Purwanto, 2016). Dalam proses pembelajaran daring hal ini akan mempengaruhi motivasi belajar dan hasil belajar siswa, beberapa siswa mengalami kesulitan belajar yang berujung pada penyajian materi yang tidak diterima siswa secara baik.

Beberapa penelitian telah meneliti penggunaan pembelajaran daring sebagai metode pengajaran untuk meningkatkan motivasi belajar, namun selain motivasi belajar pembelajaran daring juga meningkatkan hasil belajar. Ada beberapa hasil penelitian yang 
telah membuktikan bahwa pembelajaran daring jika dibandingkan dengan pembelajaran di kelas konvensional lebih mampu meningkatkan motivasi belajar serta hasil belajar (Parawanti, 2019).

Berdasarkan hasil wawancara guru di MA Hidayatul Insan Palangka Raya guru merasa kurang persiapan dan lebih merasa nyaman dengan pembelajaran tatap muka, kemudian guru juga mengalami kesulitan untuk mengontrol dan menjaga suasana belajar siswa karena adanya keterbatasan guru dalam penggunaan media pembelajaran yang dapat membantu proses belajar dan alat komunikasi kurang memadai, dan ketika proses pembelajaran dan siswa yang dapat berpartisipasi dalam pembelajaran daring hanya 8-12 orang siswa dikarenakan ada beberapa siswa yang tidak memiliki alat komunikasi yang memadai untuk pembelajaran daring. Hal inilah yang menyebabkan proses pembelajaran daring kurang maksimal, media yang digunakan di sekolah hanya berupa whatsapp untuk melakukan proses pembelajaran. Proses pembelajaran ini terjadi secara internal yang sifatnya didalam diri setiap individu agar proses pembelajaran tersebut mengarah pada tercapainya tujuan pembelajaran maka dari itu seorang guru atau pengajar hendaknya merancang dengan baik dari berbagai pengalaman belajar yang bisa menciptakan perubahan tingkah laku setiap individu sesuai dengan apa yang diinginkan (Trisna, N., \& Ariani, T, 2019). Kondisi pembelajaran yang kurang maksimal menyebabkan siswa mengalami penurunan motivasi belajar bahkan mempengaruhi hasil belajar siswa dikarenakan siswa cenderung kurang memperhatikan, malas dalam mengerjakan tugas dan juga kurang minat untuk belajar.

Berdasarkan hasil sebaran angket pra-penelitian kepada siswa MA Hidayatul Insan, diperoleh hasil bahwa siswa tidak menunjukkan kurangnya motivasi ssiwa untuk mengikuti pembelajaran, malas mengerjakan tugas, lebih senang meniru jawaban teman dan mudah bosan saat pembelajaran. Dan juga sebanyak 58\% siswa harus mengikuti ujian perbaikan pada materi momentum dan impuls. Faktor lain yang menyebabkan siswa mengalami kesulitan belajar adalah siswa merasa dituntut untuk belajar mandiri, siswa yang dapat mengikuti pembelajaran daring sedikit, kurangnya respon siswa saat pembelajaran dan kurangnya fasilitas untuk belajar daring. Dan dalam pembelajaran materi momentum dan impuls siswa dinilai masih belum memahami konsep-konsep yang ada dalam materi ini sehingga hasil belajar siswa menurun dan hampir seluruh siswa mengalami remedial saat ujian. Dari permasalah di atas, peneliti berinisiatif untuk 
melakuan pembelajaran tatap muka secara online menggunakan bantuan media google meet.

Berdasarkan uraian di atas, peneliti memutuskan untuk melakukan penelitian yang berjudul "Motivasi dan Hasil Belajar Pada Pembelajaran Daring di MA Hidayatul Insan" tujuan dari penelitian ini adalah untuk mengetahui bagaimana motivasi dan hasil belajar pada pembelajaran daring di MA Hidayatul Insan”.

\section{METODE PENELITIAN}

Jenis penelitian yang akan dilakukan adalah kuantitatif deskriptif. Penelitian deskriptif merupakan penelitian yang berusaha mendeskripsikan dan menginterpretasikan sesuatu, misalnya kondisi atau hubungan yang ada, pendapat yang berkembang, proses yang sedang berlangsung, akibat atau efek yang terjadi atau tentang kecenderungan yang tengah berlangsung. Penelitian ini bertujuan untuk memperoleh gambaran terhadap objek yang diteliti melalui data sampel (Arikunto, 2006).

Penelitian ini dilakukan pada MA Hidayatul Insan Palangka Raya pada Tahun Ajaran 2019/2020 semester II. Pengambilan sampel secara purposive sampling yaitu teknik pengambilan sampel dengan pertimbangan tertentu (Sugiyono, 2011). Sampel yang digunakan adalah kelas X MA Hidayatul Insan Palangka Raya yang berjumlah 10 orang dengan pertimbangan bahwa kelas tersebut belum diajarkan materi yang akan digunakan dan mengikuti pembelajaran daring.

Teknik pengumpulan data dilakukan dengan menggunakan instrumen penelitian. Instrumen yang digunakan untuk penelitian ini, yaitu (1) kuesioner (angket) motivasi belajar sebanyak 25 pernyataan yang digunakan untuk mengukur motivasi belajar siswa setelah menerima pembelajaran daring; (2) tes hasil belajar siswa ranah kognitif sebanyak 10 soal essay yang digunakan untuk mengamati bagaimana hasil belajar siswa setelah diberikan pembelajaran daring. Instrumen yang digunakan pada penelitian ini telah diuji keabsahan datanya. Uji keabsahan instrumen yang dilakukan meliputi uji validitas, reliabilitas, tingkat kesukaran dan daya beda pembeda. Analisis motivasi belajar siswa dilihat dari rentang tiap kategori ditetapkan menggunakan persamaan statistik yang telah disesuaikan dengan data (Sugiyono, 2011). Jumlah aspek yang diamati adalah 15 aspek, maka:

Skor maksimal $: 25 \times 5=125$ 
Skor minimal $: 25 \times 1=25$

Jumlah kategori $\quad$ :5

Interval $=\frac{\text { skor maksimal }- \text { skor minimal }}{\text { jumlah kategori }}$

Interval $=\frac{125-25}{5}=20$

Berikut tabel klasifikasi skor motivasi sesuai dengan rentang skor 25 pernyataan, yaitu:

Tabel 1. Klasifikasi Skor Motivasi

\begin{tabular}{cc}
\hline Skor & Kategori \\
\hline $25-44$ & Sangat rendah \\
\hline $45-64$ & Rendah \\
\hline $65-84$ & Sedang \\
\hline $85-104$ & Tinggi \\
\hline $105-124$ & Sangat tinggi \\
\hline
\end{tabular}

\section{HASIL DAN PEMBAHASAN}

\section{Motivasi Belajar}

Berdasarkan hasil penelitian motivasi belajar siswa selama proses pembelajaran berlangsung dapat diketahui menggunakan angket motivasi belajar siswa. Angket motivasi belajar siswa yang digunakan terdiri dari 8 indikator yang disusun dalam 25 pernyataan. Data angket motivasi belajar siswa digunakan untuk mengetahui motivasi belajar pada pembelajaran daring. Analisis data angket motivasi belajar siswa menggunakan Microsoft Excel 2016. Rekapitulasi skor motivasi belajar siswa dari pemberian angket terhadap 10 orang siswa dapat dilihat pada tabel 2. berikut:

Tabel 2. Rekapitulasi Skor Motivasi Belajar Siswa

\begin{tabular}{cccc}
\hline No. & Responden & Skor & Kategori \\
\hline 1 & AKP & 70 & Sedang \\
\hline 2 & EP & 66 & Sedang \\
\hline 3 & J & 70 & Sedang \\
\hline 4 & MAN & 68 & Sedang \\
\hline 5 & MFA & 64 & Rendah \\
\hline 6 & NPP & 70 & Sedang \\
\hline 7 & PCN & 71 & Sedang \\
\hline 8 & RAM & 69 & Sedang \\
\hline 9 & RA & 64 & Rendah \\
\hline
\end{tabular}

Puplished at https://ojs.stkippgri-lubuklinggau.ac.id/index.php/SJPIF 


\begin{tabular}{cccc}
\hline 10 & WDW & 70 & Sedang \\
\hline & Rata-Rata & 68.20 & Sedang
\end{tabular}

Tabel 2 menunjukkan skor dari masing-masing motivasi belajar siswa pada pembelajaran daring. Tabel di atas juga dapat dilihat bahwa perolehan skor tertinggi motivasi belajar siswa pada pembelajaran daring adalah 71 dengan kategori sedang dan skor terendah 64 dengan kategori motivasi belajar rendah. Dari 10 orang siswa yang telah mengisi angket pernyataan tentang motivasi belajar siswa pada pembelajaran daring di MA Hidayatul Insan diperoleh 8 orang siswa yang memiliki motivasi dengan kategori sedang dan 2 orang dengan kategori rendah. Berdasarkan hasil analisis angket secara keseluruhan dapat disimpulkan bahwa sebagian besar memiliki motivasi belajar dengan kategori sedang dan sebagian kecil siswa yang memiliki kategori rendah pada pembelajaran daring. Namun dikarenakan tidak adanya siswa yang memiliki motivasi dengan kategori tinggi pada pembelajaran daring, hal ini menunjukkan bahwa diperlukan adanya motivasi untuk menunjang semangat belajar dan meraih hasil belajar yang baik juga meski pada masa pandemi

Untuk menjawab pertanyaan penelitian ini peneliti akan menjabarkan seluruh indikator terkait bagaimana motivasi belajar siswa pada pembelajaran daring di MA Hidayatul Insan yang dilihat dari 8 indikator motivasi belajar yaitu tekun menghadapi tugas, ulet menghadapi kesulitan, menunjukkan minat terhadap masalah, lebih senang bekerja mandiri, cepat bosan pada tugas-tugas rutin, dapat mempertahankan pendapat, tidak mudah melepas hal-hal yang diyakini, dan senang mencari dan memecahkan masalah. Berikut tabel skor motivasi siswa per indikator pada pembelajaran daring.

Tabel 3. Rata-Rata Skor 8 Indikator Motivasi Belajar

\begin{tabular}{cc}
\hline Indikator & Rata-Rata Skor Per Indikator \\
\hline 1 & 10.7 \\
\hline 2 & 10.9 \\
\hline 3 & 10.4 \\
\hline 4 & 10.4 \\
\hline 5 & 11.4 \\
\hline 7 & 10.2 \\
\hline 8 & 9.3 \\
\hline
\end{tabular}

Keterangan Indikator:

$1=$ Tekun menghadapi tugas

2 = Ulet menghadapi kesulitan

3 = Menunjukkan minat terhadap masalah 
4 = Lebih senang bekerja mandiri

5 = Cepat bosan pada tugas-tugas rutin

6 = Dapat mempertahankan pendapat

7 = Tidak mudah melepas hal-hal yang diyakini

8 = Senang mencari dan memecahkan masalah

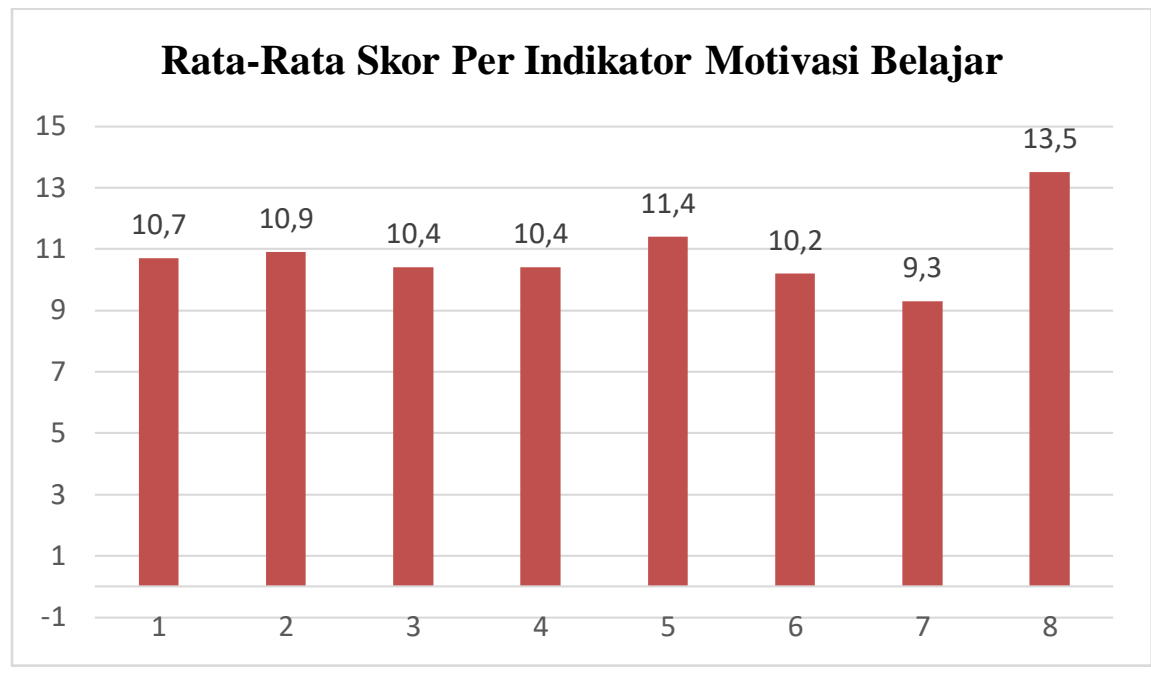

Gambar 1. Rata-Rata Skor 8 Indikator Motivasi Belajar

Berdasarkan hasil rata-rata per indikator yang dapat dilihat pada tabel 3 dan gambar 1 dapat kita ketahui bahwa pada indikator tekun menghadapi tugas nilai rata-rata sebesar 10.7, indikator ulet menghadapi kesulitan sebesar 10.9, indikator menunjukkan minat terhadap masalah sebesar 10.4, indikator lebih senang bekerja mandiri sebesar 10.4, indikator cepat bosan pada tugas-tugas rutin sebesar 11.4, indikator dapat mempertahankan pendapat sebesar 10.2, indikator tidak mudah melepas hal-hal yang diyakini sebesar 9.3, dan indikator senang memecahkan masalah sebesar 13.5. Dari hasil analisis rata-rata angket motivasi belajar siswa per indikator dapat diketahui bahwa indikator senang mencari masalah dan memecahkan masalah memiliki nilai rata-rata paling tinggi, hasil analisis menyimpulkan bahwa pada pembelajaran daring sekalipun siswa masih memiliki motivasi dan semangat yang lumayan tinggi untuk memecahkan masalah, hal ini dapat dilihat dari siswa yang merasa tertantang saat menemukan soalsoal sulit dan siswa akan mencari jawaban dari berbagai buku penunjang pembelajaran ataupun internet. Sedangkan untuk nilai rata-rata per indikator terendah adalah indikator tidak mudah melepas hal-hal yang diyakini. Hal ini membuktikan bahwa siswa memiliki motivasi dan semangat yang bagus, karena siswa tidak mudah melepas hal-hal yang mereka yakini saat pembelajaran daring. 
Motivasi sangat penting dalam kegiatan belajar mengajar, sebab adanya motivasi dapat mendorong semangat belajar siswa dan sebaliknya kurangnya motivasi akana melemahkan semangat belajar (Salsabila, 2020). Dari hal tersebut dapat dipahami bahwa betapa pentingnya motivasi belajar pada siswa meski dalam kondisi pandemi yang mengharuskan siswa dalam mengikuti proses pembelajaran daring. Siswa yang memiliki motivasi belajar yang baik tentu akan berusaha untuk mencapai hasil belajar yang baik, sebaliknya jika siswa yang memiliki motivasi rendah maka akan selalu merasa bosan dan tidak tertarik saat mengikuti proses pembelajaran di kelas. Dan masih ada faktor-faktor yang mempengaruhi motivasi siswa yakni jaringa internet yang kurang memadai dan banyaknya tugas sekolah yang diberikan oleh guru.

\section{Hasil Belajar}

Tes kemampuan hasil belajar ranah kognitif digunakan untuk mengetahui hasil belajar siswa pada pembelajaran daring. Hasil belajar siswa ranah kognitif dapat diketahui menggunakan tes berbentuk uraian (essay) sebanyak 10 soal. Instrumen yang digunakan sudah divalidasi dan diuji cobakan sebelum digunakan untuk mengambil data. Analisis data angket hasil belajar siswa menggunakan Microsoft Excel 2016. Rekapitulasi nilai hasil belajar siswa dari pemberian tes hasil belajar pada 10 orang siswa dapat dilihat pada tabel 4 berikut.

Tabel 4. Rekapitulasi Skor Tes Hasil Belajar Siswa

\begin{tabular}{cccc}
\hline No. & Responden & Skor & Ketuntasan \\
\hline 1 & AKP & 89 & Tuntas \\
\hline 2 & EP & 82 & Tuntas \\
\hline 3 & J & 86 & Tuntas \\
\hline 4 & MAN & 83 & Tuntas \\
\hline 5 & MFA & 76 & Tuntas \\
\hline 6 & NPP & 70 & Belum Tuntas \\
\hline 7 & PCN & 83 & Tuntas \\
\hline 8 & RAM & 79 & Tuntas \\
\hline 9 & RA & 60 & Belum Tuntas \\
\hline 10 & WDW & 65 & Belum Tuntas \\
\hline & Rata-Rata & 77.3 &
\end{tabular}

Keterangan : $\mathrm{KKM}=75$

Tabel 4 menunjukkan bahwa Hasil belajar siswa pada pembelajaran daring diukur dengan menggunakan tes hasil belajar ranah kognitif siswa sebanyak 10 soal dan dapat dilihat berdasarkan tabel di atas bahwa menunjukkan skor tes hasil belajar per siswa, didapatkan bahwa terdapat 3 orang siswa yang belum tuntas dan 7 orang siswa yang 
sudah tuntas pada pembelajaran daring. Dengan nilai terendah yang didapat adalah 60 dan nilai tertinggi yang didapat adalah 89 .

Untuk menjawab pertanyaan penelitian ini peneliti akan menjabarkan seluruh indikator terkait bagaimana hasil belajar siswa pada pembelajaran daring di MA Hidayatul Insan yang dilihat dari 4 indikator hasil belajar siswa pada materi momentum dan impuls. Berikut tabel rata-rata skor siswa per indikator pada pembelajaran daring.

Tabel 5. Rata-Rata Skor Hasil Belajar Per Indikator

\begin{tabular}{cc}
\hline Indikator & Rata-Rata Skor Per Indikator \\
\hline 1 & 32,7 \\
\hline 2 & 22,6 \\
\hline 3 & 17.3 \\
\hline 4 & 6.5
\end{tabular}

Keterangan Indikator:

1 = Mampu mengidentifikasikan konsep impuls, momentum, dan peristiwa tumbukan dalam kehidupan sehari-hari.

2 = Mampu menganalisis hubungan momentum dan impuls.

3 = Mampu menerapkan hukum kekekalan momentum pada peristiwa tumbukan.

4 = Mampu menganalisis peristiwa tumbukan lenting sempurna, lenting sebagian dan tidak lenting.

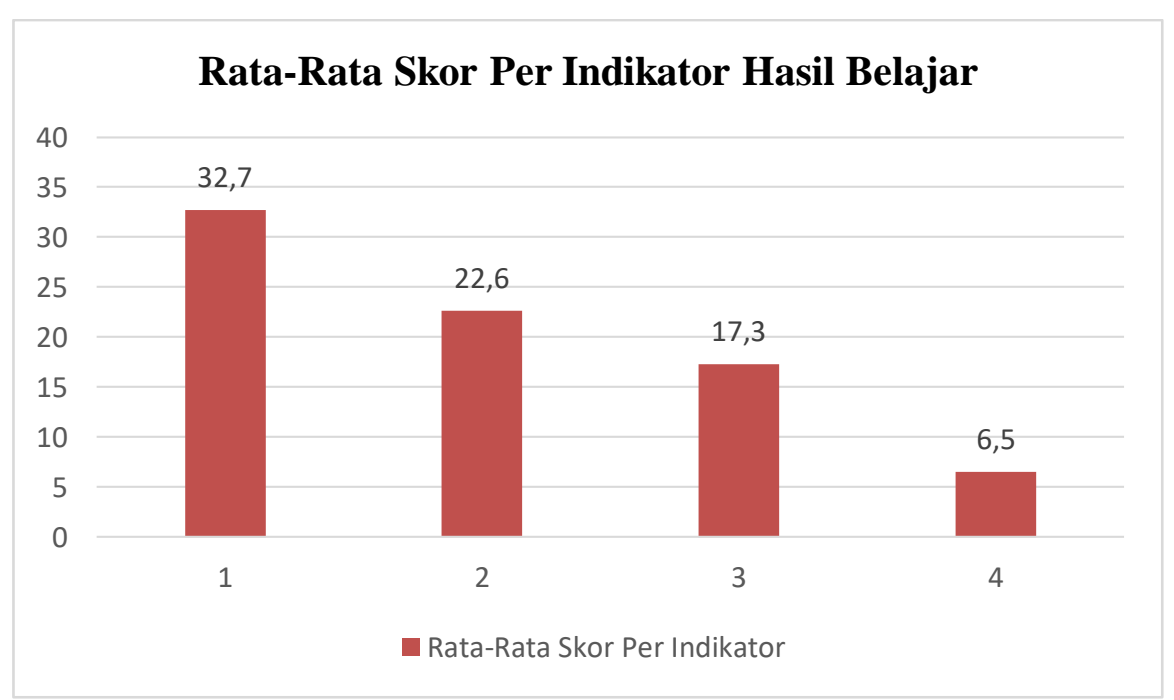

Gambar 2. Rata-Rata Skor Hasil Belajar Per Indikator

Hasil analisis per indikator, didapatkan bahwa pada indikator ketiga yaitu mampu menerapkan hukum kekekalan momentum pada peristiwa tumbukan didapatkan bahwa terdapat 9 orang yang memiliki skor rata-rata di atas 7 dan 1 orang yang memiliki skor rata-rata di bawah 7 . Hal ini dapat disimpulkan bahwa indikator ini memiliki rata-rata 
terbesar dan siswa telah mampu untuk menerapkan hukum kekekalan momentum pada peristiwa tumbukan dalam kehidupan sehari-hari. Sedangkan untuk skor rata-rata terendah terdapat pada indikator 4 yaitu mampu menganalisis peristiwa tumbukan lenting sempurna, lenting sebagian dan tidak lenting. Pada indikator ini didapatkan bahwa ada 5 orang siswa yang memiliki skor di atas 7 dan 5orang siswa dengan rata-rata skor di bawah 7. Hal ini menunjukkan bahwa pada indikator ini masih banyak terdapat siswa yang belum dapat menganalisis peristiwa tumbukan lenting sempurna, lenting sebagian dan tidak lenting.

Indikator yang dinilai dalam penelitian ini termasuk dalam teori hasil belajar pada aspek kognitif yaitu menjelaskan, menerapkan dan menganalisis. Hal ini sesuai dengan pendapat Nasrah \& Muafiah (2020) siswa diharapkan dapat mengingat, memahami, menganalisis, menyimpulkan dan menerapkan suatu materi yang dipelajari. Hasil belajar siswa dipengaruhi oleh beberapa hal, salah satunya adalah cara guru dalam menyampaikan materi pelajaran. Ketika guru menyampaikan materi dengan suasana yang menyenangkan maka siswa mudah dalam menerima materi yang diajarkan.

\section{SIMPULAN DAN SARAN}

Berdasarkan hasil analisis dan pembahasan diperoleh kesimpulan sebagai berikut:

1. Motivasi belajar siswa pada pembelajaran daring diperoleh sebanyak 8 orang siswa dengan persentase $80 \%$ pada kategori sedang dan 2 orang siswa dengan persentase $20 \%$ memiliki motivasi belajar siswa dengan kategori rendah. Dari analisis data di atas menunjukkan bahwa rata-rata motivasi siswa tergolong pada kategori sedang dengan jumlah rata-rata sebesar 68,2.

2. Hasil belajar siswa menunjukkan bahwa terdapat 3 orang siswa yang belum tuntas dan 7 orang siswa sudah tuntas pada pembelajaran daring. Dengan persentase ketuntasan $70 \%$ dan rata-rata keseluruhan skor siswa adalah 77,3. Hal ini membuktikan bahwa hasil belajar siswa pada pembelajaran daring termasuk dalam kategori tinggi. Indikator yang memiliki skor rata-rata terendah adalah indikator mampu menganalisis peristiwa tumbukan lenting sempurna, lenting sebagian dan tidak lenting. Sedangkan indikator yang memiliki skor rata-rata tertinggi adalah indikator mampu menerapkan hukum kekekalan momentum pada peristiwa tumbukan. 


\section{DAFTAR PUSTAKA}

Arikunto, S. (2006). Prosedur Suatu Pendekatan Praktik. PT Rineka Cipta.

Bloom, B.(1984). The Sigma Problem: The Search for Methods of Group Instruction as Effective as on-to-one Tutoring. Educational Researcher, 13(6), 4-16.

Chadwick, A. (2003). Interaction between States and Citizens in the Age of theiInternet:“e-Government" in the United States, Britain, and the European Union. Governance, 16(2), 271-300.

Close, E. W., Conn, J., \& Close, H. . (2016). Becoming physics people: Development of integrated physics identity through the Learning Assistant experience. Physical Review Physics Education Research, 12(1), 010109.

Darmayanti, T., Setiani, M. Y., \& Oetojo, B. (2007). E-learning pada pendidikan jarak jauh: konsep yang mengubah metode pembelajaran di perguruan tinggi di Indonesia. Jurnal Pendidikan Terbuka Dan Jarak Jauh, 8(2), 99-113.

Dede, S. (2008). Theoretical perspectives influencing the use of information technology in teaching and learning. In International handbook of information technology in primary and secondary education. In International handbook of information technology in primary and sec. Springer, Boston MA, 43-62.

Fathurrohman, M. (2017). Belajar dan Pembelajaran Modern: Konsep Dasar, Inovasi dan Teori Pembelajaran. Garudhawaca.

Gumay, O. P. U., Ariani, T., \& Putri, G. A. (2020). Development of Physics Modules Based on Inquiry in Business and Energy Subjects. Kasuari: Physics Education Journal (KPEJ), 3(1), 46-60.

Jamaludin, J., Purba, R. ., Effendy, F., Muttaqin, M., Raynonto, M. ., Chamidah, D., \& Puspita, R. (2020). Tren Teknologi Masa Depan. Yayasan Kita Menulis.

Kusmana, A. (2017). E-learning dalam Pembelajaran. Lentera Pendidikan: Jurnal Ilmu Tarbiyah Dan Keguruan, 14(1), 35-51.

Martens, R., Gulikers, J., \& Bastiaens. (2004). The impact of intrinsic motivation on elearning in authentic computer tasks. Jornal of Computer Assisted Learning, 20(5), $368-376$.

Nasrah, \& Muafiah, A. (2020). Analisis Motivasi Belajar dan Hasil Belajar Daring Mahasiswa pada Masa Pandemik Covid-19. Journal of Computer Assisted Learning, 207-213.

O’Donnell, E., Lawless, S., Sharp, M., \& Wade, V. . (2015). A review of personalised elearning: Towards supporting learner diversity. International Journal of Distance Education Technologies (IJDET), 13(1), 22-47.

Parawanti, A. (2019). Pengaruh Pembelajaran Berbasis E-Learning Model Blended Learning Terhadap Motivasi Belajar Mahasiswa Program Studi Pendidikan Agama Islam Negeri (IAIN) Parepare. In Doctoral dissertation. 
Paulsen, M. ., Nipper, S., \& Holmberg, C. (2003). Online education: Learning management systems: Global e-learning in a scandinavian perspective.

Purwanto. (2016). Evaluasi Hasil Belajar. Pustaka Belajar.

Raiser, R. . (2001). A history of instructional design and technology: Part iI: A history of instructional media. Educational Technology Research and Development, 49(1), 5364.

Salsabila, F. (2020). Analisis Motivasi Belajar IPA Peserta Didik pada Pembelajaran ELearning Class di SMPIT Nidaul Hikmah Salatiga Selama Masa Pandei Covid-19. Institut Agama Islam Negeri Indonesia.

Saputra, H. ., Ismet, F., \& Andrizal. (2018). Pengaruh Motivasi Terhadap Hasil Belajar Siswa SMK. Jurnal Inovasi Dan Teknologi, 18(1).

Sardiman, A. (2008). Interaksi dan Motivasi Belajar Mengajar. Rajawali Pers.

Sugiyono. (2011). Metodologi Penelitian Pendidikan. Alfabeta.

Sulistyaningsih, D., Mawarsari, V. ., \& Hidayah, I. (2017). Manipulatives implementation for supporting learning of mathematics for prospective teachers. In iJournal iof iPhysics: Conference Series. IOP Publishing, 824(1), 012047.

Trisna, N., \& Ariani, T. (2019). Model direct instruction dengan teknik probing prompting: Dampak terhadap hasil belajar fisika siswa kelas X SMA Negeri 4 Lubuklinggau Tahun Pelajaran 2018/2019. Silampari Jurnal Pendidikan Ilmu Fisika, 1(1), 24-37.

Zubaidah, S. (2016). Keterampilan abad ke-21: Keterampilan yang diajarkan melalui pembelajaran. In Seminar Nasional Pendidikan, 2 No. 2, 1-17. 